University of Nebraska - Lincoln

DigitalCommons@University of Nebraska - Lincoln

2014

\title{
Spatial Accuracy of Climate Networks: A Case Study in Nebraska
}

\author{
Andrea J. Coop \\ University of Nebraska-Lincoln, andreajcoop@gmail.com \\ Kenneth Hubbard \\ University of Nebraska-Lincoln, khubbard1@unl.edu \\ Martha Shulski \\ University of Nebraska-Lincoln, mshulski3@unl.edu \\ Jinsheng You \\ University of Nebraska-Lincoln, jyou2@unl.edu \\ David B. Marx \\ University of Nebraska-Lincoln, david.marx@unl.edu
}

Follow this and additional works at: https://digitalcommons.unl.edu/natrespapers

Part of the Natural Resources and Conservation Commons, Natural Resources Management and Policy Commons, and the Other Environmental Sciences Commons

Coop, Andrea J.; Hubbard, Kenneth; Shulski, Martha; You, Jinsheng; and Marx, David B., "Spatial Accuracy of Climate Networks: A Case Study in Nebraska" (2014). Papers in Natural Resources. 583.

https://digitalcommons.unl.edu/natrespapers/583

This Article is brought to you for free and open access by the Natural Resources, School of at DigitalCommons@University of Nebraska - Lincoln. It has been accepted for inclusion in Papers in Natural Resources by an authorized administrator of DigitalCommons@University of Nebraska - Lincoln. 


\title{
Spatial Accuracy of Climate Networks: A Case Study in Nebraska
}

\author{
ANDREA J. COOP \\ School of Natural Resources, University of Nebraska—Lincoln, Lincoln, Nebraska \\ Kenneth G. HubBard, Martha D. Shulski, AND Jinsheng You \\ High Plains Regional Climate Center, University of Nebraska-Lincoln, Lincoln, Nebraska \\ DAVID B. MARX \\ Department of Statistics, University of Nebraska_Lincoln, Lincoln, Nebraska
}

(Manuscript received 23 September 2013, in final form 1 May 2014)

\begin{abstract}
Climate data are increasingly scrutinized for accuracy because of the need for reliable input for climaterelated decision making and assessments of climate change. Over the last 30 years, vast improvements to U.S. instrumentation, data collection, and station siting have created more accurate data. This study explores the spatial accuracy of daily maximum and minimum air temperature data in Nebraska networks, including the U.S. Historical Climatology Network (HCN), the Automated Weather Data Network (AWDN), and the more recent U.S. Climate Reference Network (CRN). The spatial structure of temperature variations at the earth's surface is compared for timeframes 2005-09 for CRN and AWDN and 1985-2005 for AWDN and HCN. Individual root-mean-square errors between candidate station and surrounding stations were calculated and used to determine the spatial accuracy of the networks. This study demonstrated that in the 5-yr analysis CRN and AWDN were of high spatial accuracy. For the 21-yr analysis the AWDN proved to have higher spatial accuracy (smaller errors) than the HCN for both maximum and minimum air temperature and for all months. In addition, accuracy was generally higher in summer months and the subhumid area had higher accuracy than did the semiarid area. The findings of this study can be used for Nebraska as an estimate of the uncertainty associated with using a weather station's data at a decision point some distance from the station.
\end{abstract}

\section{Introduction and background}

Documentation of the present weather is a necessity for decision makers in the transportation, business, engineering, insurance, litigation, and agricultural sectors (Goody et al. 2002). The network design (e.g., the appropriate variables to monitor, the spatial and temporal resolution, and the sensor accuracy) must reflect the intended purpose of the network (Melvin et al. 2008). In recent years, the need for high-quality climate data that are regionally, nationally, and globally representative has increased substantially as a result of the spotlight on climate change and its possible impacts. There are three networks included in this study as described below.

Corresponding author address: Kenneth G. Hubbard, High Plains Regional Climate Center, 703 Hardin Hall, University of Nebraska-Lincoln, Lincoln, NE 68583-0997.

E-mail: khubbard1@unl.edu
The longest-running U.S. observation network is the Cooperative Observer Program (COOP), which was established in the 1890s and relies on thousands of volunteers to record daily maximum and minimum air temperature and total daily rainfall. By 1958 , the COOP program had grown to nearly 14000 observers. The variables currently measured are maximum and minimum air temperature, 24-h precipitation total, snowfall, and snow depth. As technology improved over time, the bias created by different observation times, dissimilar instrumentation, and multiple station relocations became more evident (Wu et al. 2005; Wendland and Armstrong 1993). Some of the COOP data are included in the U.S. Historical Climatology Network (HCN). Although there are biases present in the daily $\mathrm{HCN}$ data, the network will be included here because its spatial accuracy has not been previously documented.

In response to agricultural needs, nonfederal near-realtime networks were developed on state and regional scales (Meyer and Hubbard 1992; Hoogenboom and 
Gresham 1997). The need for unbiased, spatially dense, and diverse variables (e.g., solar radiation, wind speed, and humidity observations) to power local decision-making models was fulfilled by these networks. In Nebraska, the University of Nebraska developed the Automated Weather Data Network (AWDN) in the early 1980s (Hubbard et al. 1983; Meyer and Hubbard 1992). With automation, biases (time of observation, number reversals, etc.) were largely eliminated. Fiebrich (2009) described additional development of automated weather stations in the United States.

The U.S. government deployed the Climate Reference Network (CRN) in 2004 as a response to the need for high-quality and representative datasets to address national climate change (Diamond et al. 2013). Learning from the inconsistencies in the COOP/HCN data, CRN stations were installed in areas where construction, urbanization, or any other microclimate bias will not affect current or future measurements. Three redundant measurements of temperature and two measures of precipitation are collected to recognize and address any sensor differences and to ensure the credibility of the measurements. Calibration and maintenance are top priorities for each weather station to ensure the accuracy of the measurements taken.

The recent literature has addressed issues related to the spatial accuracy (the accuracy of estimates obtained from the network at points between weather stations) of networks. Gallo (2005) looked at the differences in air temperatures for paired CRN stations. Melvin et al. (2008) linked the spatial statistics of the atmosphere directly to the intended purpose of a network. Vose and Menne (2004) proposed a method for determining stationdensity requirements for a climate network. Hubbard (1994) characterized the spatial variability of daily weather observations in the high plains for several variables including temperature, humidity, solar radiation, wind speed, soil temperature, and precipitation. Holder et al. (2006) compared collocated automated and observer data in North Carolina. Accuracy of instrumentation is an extremely important aspect for each network and, in part, determines the quality of the data that are collected from that network. Routine calibration, maintenance, and replacement of instruments are the key to maintaining the integrity of network data.

In a Great Plains state like Nebraska, advection associated with frontal activity leads to highly variable weather. In addition, local effects are present as a result of the patterns of topography and subsequent diurnal inversions. When correlation or other statistical measures are plotted according to the distance of separation between stations, the resulting graph or map can be used to answer questions such as, How close do the stations need to be to achieve a certain network accuracy goal? The spatial analysis can also determine where any new stations should be located in the existing network. Spatial-accuracy studies, in the past, focused on the desired spatial density of networks that is necessary to meet the goal of climate monitoring (Vose and Menne 2004; Janis et al. 2004). Vose and Menne (2004) describe the preferred spatial density for the CRN as being highly dependent on the intended use for the data being collected.

The purpose of this study is to determine and compare the spatial accuracy in Nebraska of the three included networks: the HCN, AWDN, and CRN. In other words, how will the accuracy of an estimate decrease with distance from a station for each network? Our focus will be on answering the questions, How do the statistical measures vary with distance of separation between stations within these networks and seasonally?

\section{Data and methods}

\section{a. Datasets}

Below, a brief summary is given of each of the three networks that collected the daily data used in this study.

\section{1) U.S. Historical Climatology Network}

After it was realized that there are biases present in the COOP station network, a subset of stations, known as the U.S. Historical Climatology Network, was identified in the mid-1980s by the National Oceanic and Atmospheric Administration (NOAA) National Climatic Data Center (NCDC) and the U.S. Department of Energy Carbon Dioxide Information Analysis Center "in response to the need for an accurate, unbiased, modern historical climate record for the United States" (Menne et al. 2013). The HCN includes COOP stations with the longest records and least number of station moves. Adjustments of HCN monthly data were implemented to reduce heterogeneity and will be discussed here because the factors causing the monthly heterogeneity are also present in the daily $\mathrm{HCN}$ data used herein. Inconsistencies within the HCN monthly dataset caused by time of observation changes, instrumentation changes, station relocations, and observer bias have been scrutinized over the past 20 years (Pielke et al. 2007; Davey and Pielke 2005; Hubbard et al. 2004; Vose and Menne 2004; Wendland and Armstrong 1993; Guttman and Baker 1996). Adjustments to the monthly data have been made to produce a dataset that is less heterogeneous (Lawrimore et al. 2011). The U.S. HCN consists of over 1200 weather stations. This network collects maximum and minimum air temperature, precipitation, snowfall, and snow depth (Menne et al. 2009). 
The Maximum Minimum Temperature System (MMTS) replaced most of the liquid-in-glass (LIG) thermometers in the mid-1980s, and the MMTS uses a single thermistor that continually senses the current temperature and preserves the highest (maximum) and lowest (minimum) values that were measured since the instrument was last reset. The MMTS sensor is shielded from direct sunlight by a white plastic louvered "beehive" about $25 \mathrm{~cm}$ high and about $20 \mathrm{~cm}$ in diameter. LIG thermometers traditionally were installed within a white, wooden, cottonregion shelter (CRS), with a double roof and louvered sides, about $50 \mathrm{~cm} \times 90 \mathrm{~cm}$ horizontally and $80 \mathrm{~cm}$ high. The MMTS instruments are about $1.7 \mathrm{~m}$ above the ground. The thermal mass of the sensor and the microclimate inside the shelter (Lin et al. 2001) will determine the response time and will lead to a difference in both maximum and minimum temperature recording between the CRS and MMTS platforms. According to Menne et al. (2009), revisions, such as the ones needed because of the replacement of thermometers, have reduced the uncertainty of the monthly $\mathrm{HCN}$ dataset.

NCDC has since released a daily dataset from the HCN stations (Menne et al. 2012). The daily unadjusted HCN dataset can be obtained online from the NCDC (http://www.ncdc.noaa.gov/oa/climate/research/ushcn/ daily.html). This dataset contains maximum and minimum temperatures along with precipitation totals from 138 of the "most reliable, internally consistent, and unbiased" stations (http://cdiac.ornl.gov/epubs/ndp/ushen/ daily_doc.html). The Daily HCN data were used in this study. The HCN daily dataset differs from the $\mathrm{HCN}$ monthly dataset because no daily bias adjustments have been applied to account for instrumentation changes, observation changes, or station relocations. Thus, the daily datasets for $\mathrm{HCN}$ at this time are not homogeneous. Some of the data from HCN are still collected by the traditional daily observation forms sent to NCDC at the end of the month, but many of the station observers now key in the daily observations through an Internet interface called WxCoder III (http://wxcoder.org/), which provides some quality-control feedback during data entry.

\section{2) Automated Weather Data Network}

The Automated Weather Data Network originated at the University of Nebraska and developed into a regional cooperative effort among states in the region. This automated weather network was initially formed in 1981 in support of agricultural activity in the state of Nebraska (Hubbard et al. 1983). AWDN sites (http:// www.hprcc.unl.edu/awdn/) record hourly and daily data for air temperature and humidity, soil temperature, wind speed and direction, solar radiation, precipitation, and soil water content. AWDN weather stations are sited and maintained by other states in the region: Colorado, Iowa, Kansas, Minnesota, Missouri, Montana, North Dakota, Nebraska, South Dakota, and Wyoming. Communications with stations in the network are routed through a central computer. The communications began in 1981 using land lines and telephone modems and now involve the use of remote connections between local area networks and cellular telephone units through static Internet-protocol addresses. The newer $4 \mathrm{G}$ modems are capable of higher-speed communications and can support real-time data collection.

\section{3) U.S. Climate Reference Network}

The U.S. Climate Reference Network is a network of 114 weather stations in the contiguous United States plus 6 stations in Alaska and 2 stations in Hawaii; the stations are installed and maintained by NOAA. CRN stations were developed and deployed to create a network that would confidently identify climate change throughout the nation (http://www.ncdc.noaa.gov/crn). Each CRN weather station takes three independent measurements of temperature and two measurements of precipitation. Solar radiation, surface radiative temperature, surface winds, atmospheric relative humidity, soil temperature, and soil water content are auxiliary measurements at each CRN site. According to NCDC, "[e]very USCRN observing site is equipped with a standard set of sensors, a data logger and a satellite communications transmitter, and at least one weighing rain gauge encircled by a wind shield. ... The hourly observations and the fifteen minute precipitation data are stored in a data logger attached to the tower. A GOES [Geostationary Operational Environmental Satellite] satellite transmitter sends the data to the National Climatic Data Center where the data undergo a quality control check and are placed on the Web several times a day" (http://www.ncdc.noaa.gov/crn/sitedescription.html). To ensure that this network creates an unbiased record of the national climate, routine calibration and maintenance are practiced.

\section{b. Instrumentation}

The HCN, AWDN, and CRN differ in the sensors employed to measure air temperature. The CRN temperature system includes three precision resistance thermometers (PRTs) inside an aspirated radiation shield. If one of the PRT sensor readings departs from the others, the system is checked and PRT replacement is made as needed to bring the three temperature readings back into agreement. Temperature readings are taken at a midnightto-midnight time interval. In the AWDN stations, a thermistor is used to measure the temperature inside a nonaspirated "Gill" shield. The thermistor is sampled 
every $10 \mathrm{~s}$, and the highest and lowest readings from midnight to midnight are recorded as the maximum and minimum daily air temperature, respectively. In the $\mathrm{HCN}$, the temperature measurements prior to the 1980 s were made with maximum and minimum versions of LIG thermometers located inside a CRS. The CRS is a nonaspirated shield. Those stations that transitioned to the MMTS at HCN sites measured temperature with a thermistor that recorded the 24-h maximum and minimum temperature at observation time. Observers usually choose to take either a morning or evening reading of the temperatures. Bias assessments of the MMTS system have been documented (Hubbard et al. 2005).

There are biases present in temperature readings, such as solar radiation and wind speed biases inside nonaspirated shields. The separation of LIG thermometers was a well-known but undocumented problem that is not an issue with the newer electronic thermometers. Also, the response time of the temperature sensing system and other factors will determine the type of biases present in the sensor readings for the maximum and minimum air temperature (Lin and Hubbard 2008). Beyond the electronic and design biases there are additional temperature biases in the data record. These can be caused by moving the equipment to another location without renaming or giving the station a new identification number. Also, the volunteer observers may change the time of observation (TOB) from morning to evening observations or vice versa. Secondary bias can also arise during the estimation of missing data as a result of the use of biased estimators.

The TOB biases are present only in the HCN data because both AWDN and CRN are implemented on an electronic time schedule and are capable of calculating true midnight-to-midnight observations. Likewise, the AWDN and CRN network stations are at fixed sites, unlike the HCN stations, which often change locations as necessitated by a change in observers at a USHCN site. Additional information on the performance of the different temperature sensors is available in Lin and Hubbard (2004).

\section{c. Data processing}

Maximum and minimum daily air temperature data for three climate networks in Nebraska were obtained as follows. The data were acquired from their respective website databases: NCDC (CRN and $\mathrm{HCN})$ and the High Plains Regional Climate Center (AWDN). To compare statistically between networks, only data from the same time period (same set of years) were used. Otherwise, any differences between networks could be due to the difference in weather for the different time periods.
At the time of the study, the time period available for CRN was 2005-09. A previous study (Hubbard 1994) demonstrated that 5 years is a sufficiently long duration to arrive at concentric spatial patterns whereby the spatial statistics become independent of direction. AWDN and $\mathrm{HCN}$ data were analyzed using a $21-\mathrm{yr}$ period from 1985 to 2005 because prior to 1985 there were fewer AWDN stations available.

The climate in Nebraska varies from semiarid in the west to subhumid in the east. A central station was selected for each network to form pairs that were in close proximity to each other. In addition, candidate stations for the HCN and AWDN were selected in proximity to the Nebraska CRN weather stations, which are comparatively more limited in number; only four CRN weather stations are located within Nebraska. Candidate stations were restricted to those with less than $5 \%$ missing data for the selected period. Candidate stations used in this study are shown in Fig. 1.

Data from weather stations within a radius of $500 \mathrm{~km}$ from each of the candidate stations for all three climate networks were included. Because of the large distances between the $\mathrm{CRN}$ stations, $500 \mathrm{~km}$ was chosen to ensure that the analysis for the CRN stations included a sufficient number of surrounding stations to represent the spatial variability. These neighboring stations were used to calculate the spatial accuracy of the network in the vicinity of the candidate site. Neighboring stations with more than $5 \%$ missing data for the period of record were excluded from the analysis to reduce the possible bias associated with estimates.

Missing observations from weather station sites can be estimated, and estimation procedures have been compared by Kemp et al. (1983) and You et al. (2008). The two techniques from You et al. (2008) used for estimating missing data were inverse distance weighting (IDW) and the spatial regression test (SRT). The SRT technique was used when sufficient data were available to determine statistical relationships with surrounding stations, and it was preferred because it is a nonbiased estimation (Hubbard and You 2005; You et al. 2008). In cases in which there is a long missing-data gap (e.g., 2 weeks), IDW was used.

The SRT is a quality-control approach that provides an unbiased estimate and probabilistically determined upper and lower limits on the estimate. Unlike distanceweighting techniques, this approach selects those stations that compare most favorably to the station of interest (according to the best fit between station data when no data are missing), and these may or may not be the closest stations. The IDW method is a simple distance-weighted average of the nearest stations to obtain estimates of the value at the target station. For 


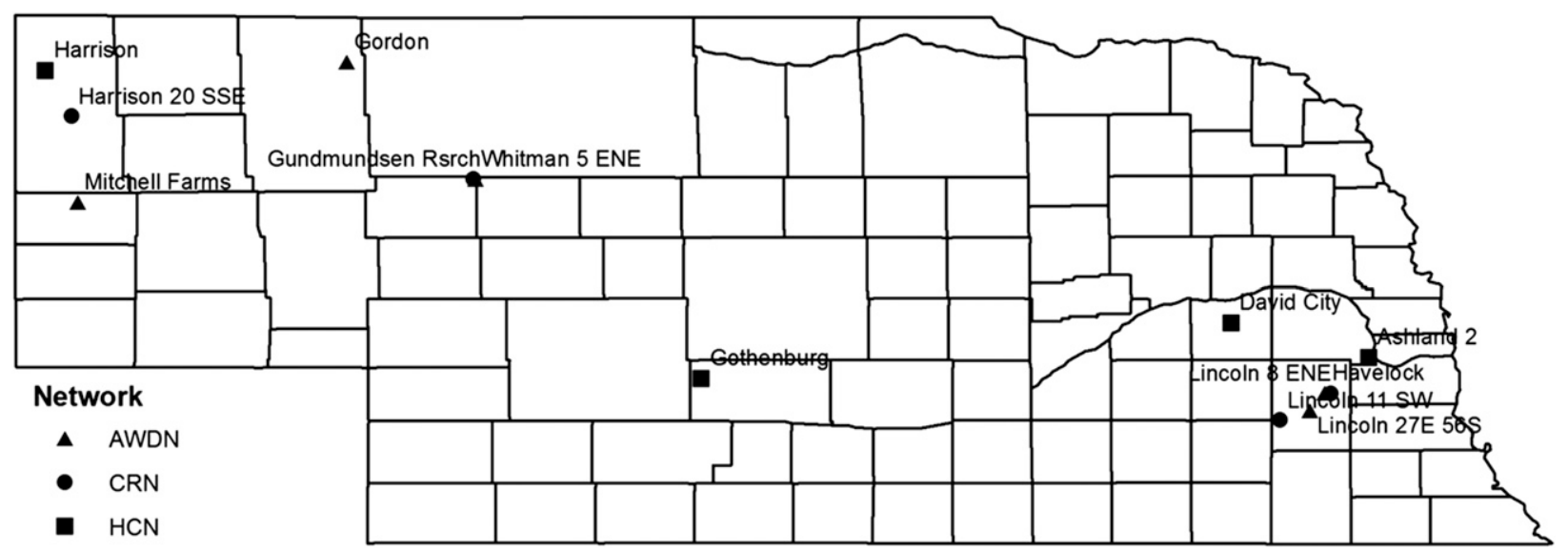

FIG. 1. Map of candidate stations for the AWDN, CRN, and HCN networks used in this study.

IDW, the formulation provides more weight to the closest stations. In reality this may not be appropriate, especially in mountainous terrain or where significantly different microclimates are close in proximity. The estimates obtained from IDW are not free from bias.

You et al. (2008) concluded that SRT calculates better estimates than IDW in the United States; the improvement of the SRT estimates relative to the IDW estimates within the Great Plains is much smaller than in areas with more topographic relief, however. To quantify the reliability of the estimations in this study, various actual observations from the record of a station were set aside and marked as missing values. Estimates for those days were then determined, and the estimated values were compared with the actual values by examining the variance explained by the estimates.

\section{d. Spatial analysis}

To find the spatial accuracy for each candidate station, it was paired in turn with each of the surrounding stations for that network to calculate the relevant statistics. The daily observations $Y$ at the candidate station were compared with the observations $X$ at each surrounding station to determine the variance $r^{2}$ and the root-mean-square-error (RMSE) for each of the months. The resulting values (e.g., RMSE) were then plotted against distance of separation from the candidate station to create a spatial RMSE graph. Values from the monthly spatial RMSE analyses were then composited, showing the relationships between RMSE, month, and distance of separation. This graph then was construed to represent the accuracy associated with using a station to estimate a value at a point as a function of the month and how far the point is from that station.

\section{Results}

Each of the four HCN stations was paired with a nearby AWDN station to give eight candidate stations (i.e., four pairs). Another $174 \mathrm{HCN}$ stations were used as

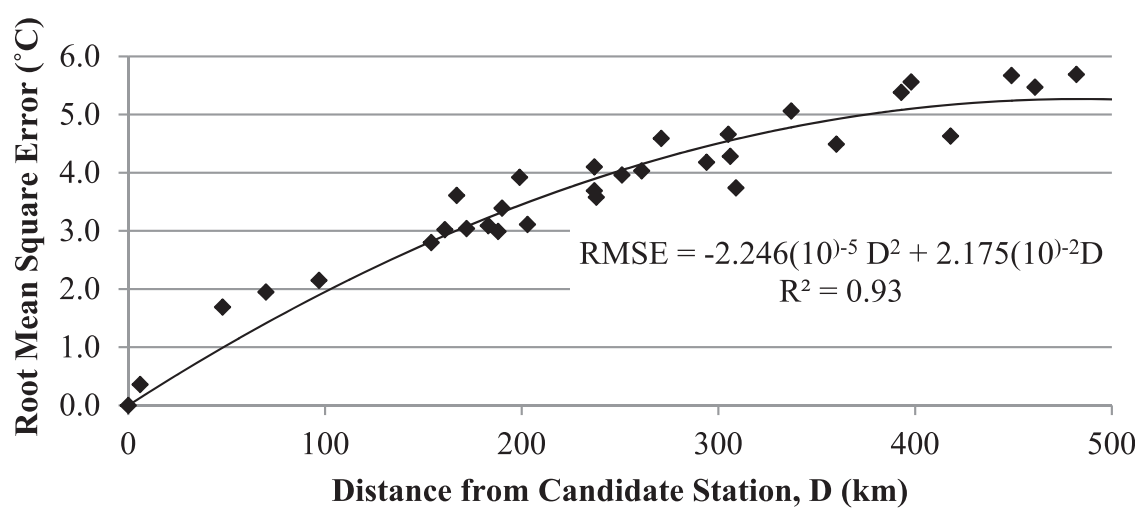

FIG. 2. Relationship between RMSE $\left({ }^{\circ} \mathrm{C}\right)$ and distance from candidate station (Mitchell Farms) to surrounding stations for maximum temperature in February. 


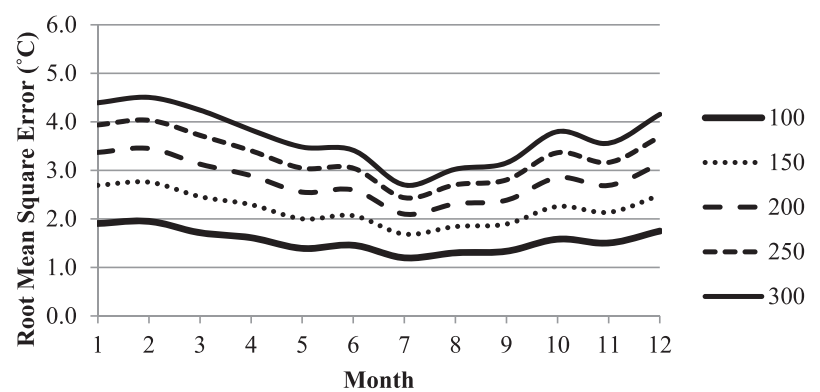

FIG. 3. RMSE $\left({ }^{\circ} \mathrm{C}\right)$ vs month for various distances $(\mathrm{km})$ from the candidate station to surrounding stations at Mitchell Farms for maximum temperature.

HCN surrounding stations (i.e., surrounding the candidate $\mathrm{HCN}$ stations). This provided about 40 station pairs for each candidate $\mathrm{HCN}$ station.

In addition, each of the four $\mathrm{CRN}$ stations was paired with a nearby AWDN station to provide another eight candidate stations. An additional $14 \mathrm{CRN}$ stations were categorized as surrounding CRN stations, and an additional 110 AWDN stations were specified as surrounding AWDN stations. The average distance from each station to its nearest neighbor was determined to be 185,52 , and $46 \mathrm{~km}$, respectively, for the CRN, HCN, and AWDN stations. Missing data were estimated, and the estimates of maximum and minimum temperature were able to explain more than $90 \%$ of the variance in tests in which observations were first assumed to be missing so that estimates could be compared with observations. This is consistent with previous results (You et al. 2008).

\section{a. Spatial RMSE}

A typical example of the spatial RMSE graph is shown for the candidate station at Mitchell Farms; see Fig. 2. This example is for maximum temperature for February. Note that each point in Fig. 2 represents a station paired with Mitchell Farms. The relationship between distance of separation and the RMSE between the station pairs in February resulted in an $r^{2}$ of $93 \%$. The regression curve shown in Fig. 2 represents the best fit to the RMSE data using a second-order polynomial in which the intercept
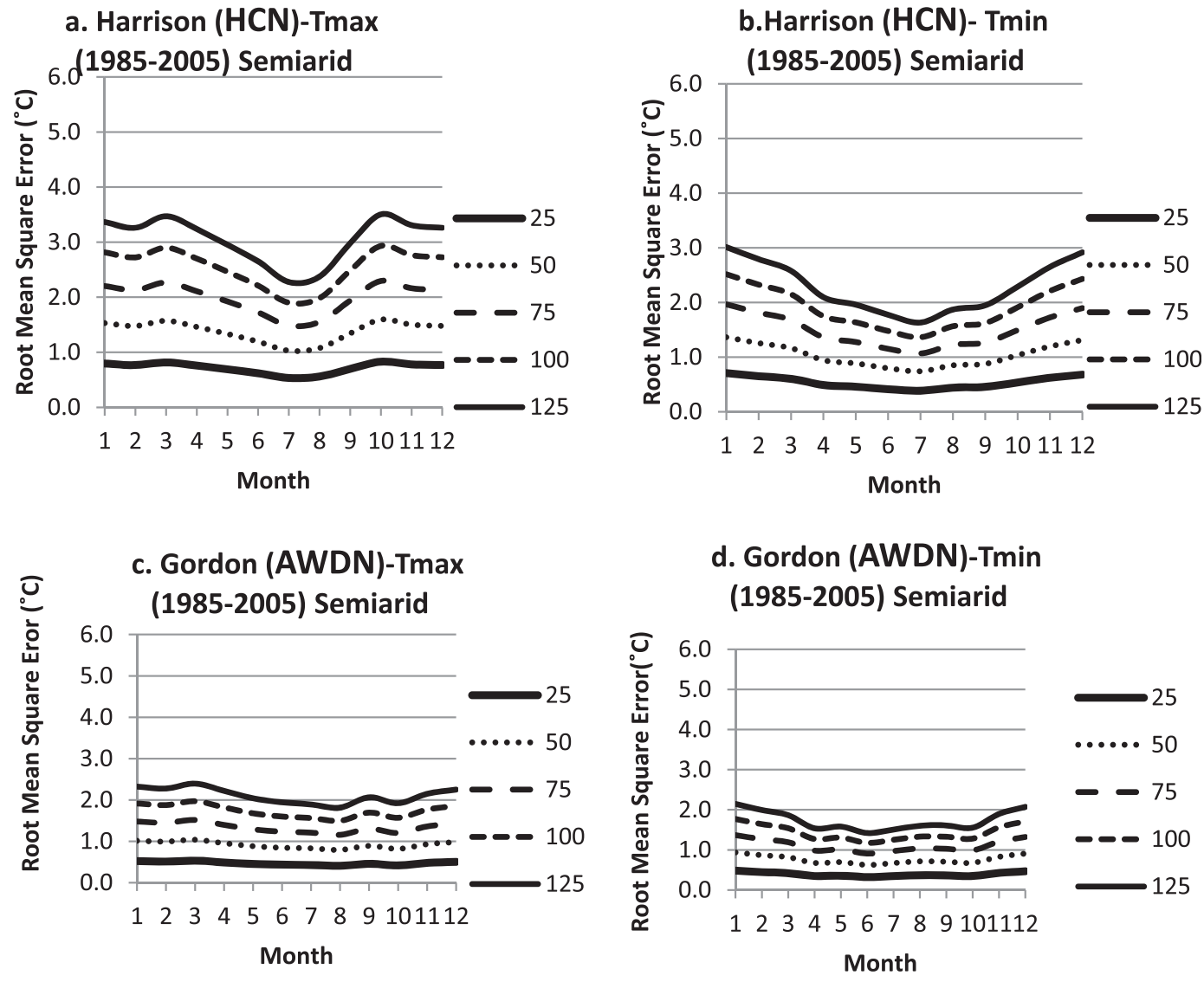

FIG. 4. RMSE $\left({ }^{\circ} \mathrm{C}\right)$ vs month for various distances $(\mathrm{km})$ from the candidate station to surrounding stations for semiarid sites for the Harrison HCN station for (a) Tmax and (b) Tmin and for the Gordon AWDN station for (c) Tmax and (d) Tmin. 
TABLE 1. Estimated RMSE $\left({ }^{\circ} \mathrm{C}\right)$ vs distance $(\mathrm{km})$ for each station in the pair (HCN and AWDN) for January and June (1985-2005). An asterisk (plus sign) indicates that the RMSE at the given distance and station is lower by at least $0.5^{\circ} \mathrm{C}\left(1.0^{\circ} \mathrm{C}\right)$ than the comparison station in the other network.

\begin{tabular}{|c|c|c|c|c|c|c|c|c|c|c|c|}
\hline \multirow[b]{2}{*}{ Candidate station by pairs } & \multirow[b]{2}{*}{ Month } & \multicolumn{5}{|c|}{$\begin{array}{l}\text { RMSE for max temperature at } \\
\text { various distances }(\mathrm{km})\end{array}$} & \multicolumn{5}{|c|}{$\begin{array}{l}\text { RMSE for min temperature at } \\
\text { various distances }(\mathrm{km})\end{array}$} \\
\hline & & 25 & 50 & 75 & 100 & 125 & 25 & 50 & 75 & 100 & 125 \\
\hline \multirow[t]{2}{*}{ Harrison $(\mathrm{HCN})$, semiarid } & Jan & 0.80 & 1.53 & 2.20 & 2.81 & 3.37 & 0.71 & 1.36 & 1.97 & 2.52 & 3.01 \\
\hline & Jun & 0.62 & 1.19 & 1.72 & 2.21 & 2.65 & 0.41 & 0.80 & 1.15 & 1.48 & 1.78 \\
\hline \multirow[t]{2}{*}{ Gordon (AWDN), semiarid } & Jan & 0.52 & $1.01 *$ & $1.48 *$ & $1.91 *$ & $2.32^{+}$ & 0.48 & 0.94 & $1.37 *$ & $1.77 *$ & $2.15^{*}$ \\
\hline & Jun & 0.43 & 0.84 & 1.23 & $1.60 *$ & $1.94 *$ & 0.32 & 0.63 & 0.91 & 1.17 & 1.42 \\
\hline \multirow[t]{2}{*}{ Ashland (HCN), subhumid } & Jan & 0.71 & 1.38 & 1.99 & 2.55 & 3.07 & 0.58 & 1.12 & 1.62 & 2.08 & 2.50 \\
\hline & Jun & 0.48 & 0.93 & 1.34 & 1.73 & 2.08 & 0.37 & 0.72 & 1.04 & 1.33 & 1.60 \\
\hline \multirow[t]{2}{*}{ Mead (AWDN), subhumid } & Jan & 0.44 & $0.86^{*}$ & $1.26^{*}$ & $1.64 *$ & $2.01^{+}$ & 0.49 & 0.95 & 1.38 & 1.79 & 2.17 \\
\hline & Jun & 0.36 & 0.70 & 1.02 & 1.32 & 1.60 & 0.32 & 0.62 & 0.90 & 1.17 & 1.42 \\
\hline \multirow[t]{2}{*}{ David City (HCN), subhumid } & Jan & 0.79 & 1.52 & 2.20 & 2.82 & 3.38 & 0.63 & 1.21 & 1.74 & 2.23 & 2.68 \\
\hline & Jun & 0.55 & 1.05 & 1.52 & 1.94 & 2.32 & 0.47 & 0.90 & 1.30 & 1.66 & 1.98 \\
\hline \multirow[t]{2}{*}{ Mead (AWDN), subhumid } & Jan & 0.44 & $0.86^{*}$ & $1.26^{*}$ & $1.64^{+}$ & $2.01^{+}$ & 0.49 & 0.95 & 1.38 & 1.79 & $2.17^{*}$ \\
\hline & Jun & 0.36 & 0.70 & 1.02 & $1.32 *$ & $1.60^{*}$ & 0.32 & 0.62 & 0.90 & 1.17 & $1.42 *$ \\
\hline \multirow[t]{2}{*}{ Gothenburg ( $\mathrm{HCN})$, semiarid } & Jan & 0.74 & 1.43 & 2.06 & 2.65 & 3.18 & 0.54 & 1.05 & 1.51 & 1.95 & 2.35 \\
\hline & Jun & 0.60 & 1.15 & 1.66 & 2.12 & 2.54 & 0.43 & 0.82 & 1.19 & 1.53 & 1.83 \\
\hline \multirow[t]{2}{*}{ Arthur (AWDN), semiarid } & Jan & 0.54 & 1.06 & $1.54 *$ & $1.99 *$ & $2.41 *$ & 0.53 & 1.02 & 1.48 & 1.91 & 2.30 \\
\hline & Jun & 0.41 & 0.80 & 1.17 & $1.51 *$ & $1.83^{*}$ & 0.36 & 0.69 & 1.00 & 1.29 & 1.55 \\
\hline
\end{tabular}

is forced through zero. This forcing through zero is consistent with a zero RMSE between collocated weather stations. The shape of the curve in Fig. 2 is typical of other months and other stations. These curves were derived for each station and every month for both maximum and minimum temperature (not shown; see Coop 2011). The many curves for a station were condensed into a single figure for each station for both maximum and minimum temperatures. An example of this condensed annual accuracy graph for maximum temperature at Mitchell Farms is shown in Fig. 3. By choosing a point along the vertical axis to represent the desired accuracy, one can move to the right to find the largest distance of separation that still meets the desired accuracy. The data for Fig. 2 are contained in the composite graph in Fig. 3 at the five points plotted for month 2 . The relatively higher RMSE in winter in comparison with summer (see Fig. 3) was found for all sites analyzed in this study.

\section{b. The 21-yr analysis (1985-2005) comparing HCN and AWDN networks}

The seasonal changes in the RMSE for the stations in the semiarid region are shown in Figs. 4a-d. For Gordon (AWDN) the separation distance to maintain an RMSE of less than $1^{\circ} \mathrm{C}$ throughout the year is $\sim 50 \mathrm{~km}$ for both maximum (Tmax) and minimum air temperature (Tmin). The HCN station (Harrison) would require a smaller distance of separation to maintain an RMSE at $1^{\circ} \mathrm{C}$ or below year-round, $\sim 25 \mathrm{~km}$ for both Tmax and Tmin.

Table 1 shows the results for the other pairings of HCN and AWDN stations. The table indicates which pairings are for semiarid western Nebraska and which are for subhumid eastern Nebraska. For minimum temperature, the RMSE in the AWDN for a western site (Arthur) is higher than the RMSE for Mead. The AWDN stations outperform the HCN stations in all seasons and at all distances, and many times the RMSE for an AWDN site is smaller than the RMSE for HCN stations by from $0.5^{\circ}$ to more than $1^{\circ} \mathrm{C}$ at the distances shown in Table 1.

\section{c. The 5-yr analysis (2005-09) comparing CRN and AWDN networks}

The results of the seasonal accuracy assessment for a subhumid (CRN and AWDN) case are shown in Figs. 5a-d for station pairings near Lincoln. The RMSE values for minimum temperature varied from $\sim 1^{\circ}$ to $3^{\circ} \mathrm{C}$ over the separation distances shown and all months. This was true for both the CRN and AWDN sites. An RMSE $\leq 2^{\circ} \mathrm{C}$ can be maintained in both CRN and AWDN stations if separation distance is no larger than $100 \mathrm{~km}$.

Figures 6a-d show the results of the seasonal accuracy assessment for a semiarid (CRN and AWDN) case for 
a. Lincoln11 SW (CRN)-Tmax (20052009) Sub-Humid

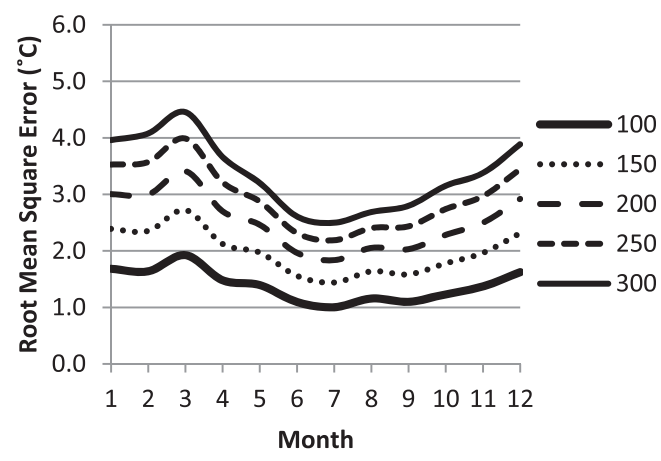

c. Lincoln 27E 56S (AWDN)-Tmax

(2005-2009) Sub-Humid

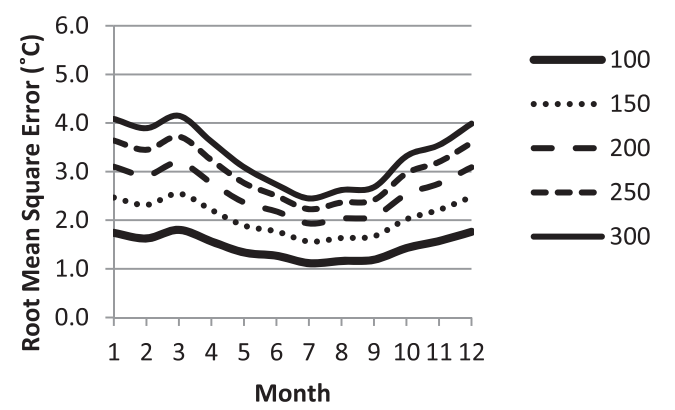

b. Lincoln11 SW (CRN)-Tmin (20052009) Sub-Humid

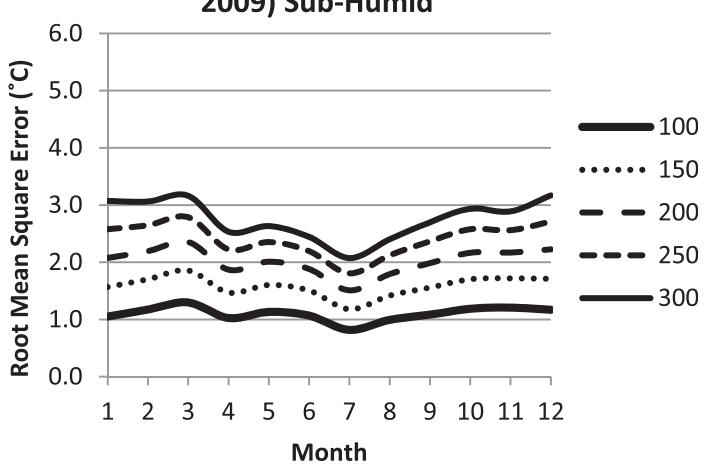

d. Lincoln 27E 56S (AWDN)-Tmin (20052009) Sub-Humid

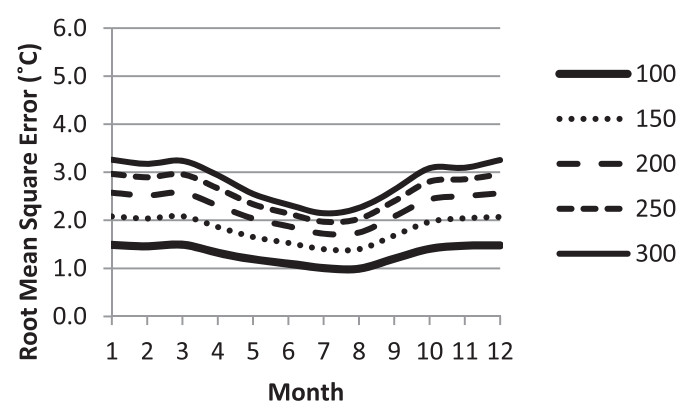

FIG. 5. RMSE $\left({ }^{\circ} \mathrm{C}\right)$ vs month for various distances $(\mathrm{km})$ from the candidate station to surrounding stations for subhumid sites for the Lincoln 11 SW CRN station for (a) Tmax and (b) Tmin and for the Lincoln 27E 56S AWDN station for (c) Tmax and (d) Tmin.

stations in western Nebraska. The RMSE values for minimum temperature varied from $\sim 1^{\circ}$ to $4^{\circ} \mathrm{C}$ over the separation distances shown and all months. These values are higher than for the subhumid case (Fig. 5), indicating that spatial variability is higher in the semiarid area. This was true for both the CRN and AWDN sites. Again an RMSE $\leq 2^{\circ} \mathrm{C}$ can be maintained in both CRN and AWDN stations if separation distance is no larger than $100 \mathrm{~km}$.

During the summer season (June-August; see Figs. 5 and 6) and, to a lesser extent, for late spring and early autumn, spatial accuracy is best; in the winter, the RMSE is higher. This is the case for all of the stations analyzed in this paper for both maximum and minimum temperature and for both semiarid and subhumid cases.

The results for pairings of other CRN and AWDN stations are shown in Table 2. It is clear that the June RMSEs are smaller than those for January, consistent with the discussion above. We also note that the semiarid values of RMSE in June at $100 \mathrm{~km}$ are higher than their RMSE counterparts at the subhumid sites; for example, Harrison 20 SSE and Whitman 5 ENE have values of 1.19 and 1.26, respectively, which are higher than the values for Lincoln 8 ENE (1.01) and Lincoln 11 SW (1.10). This tendency for semiarid RMSE to be higher than subhumid RMSE is also present in the AWDN stations shown.

The RMSEs for the CRN and AWDN pairings in Table 2 are similar, and in no case was the difference in the RMSE for any month or distance $\geq 1^{\circ} \mathrm{C}$. There were no situations for maximum temperature in which the RMSEs were different by more than $0.5^{\circ} \mathrm{C}$. There were only a few months for which the RMSE differences for minimum temperatures were larger than $0.5^{\circ} \mathrm{C}$.

\section{Discussion and conclusions}

The spatial accuracy, as defined in this study, is a representation of how spatial accuracy decreases with distance from a weather station. Not surprising is that we found that as distance from the candidate station increases, the accuracy decreases. This occurs because stations are not sampling the air mass at the same time or the same location. Thus, although the same weather 
a. Whitman 5 ENE (CRN)-Tmax (20052009) Semiarid

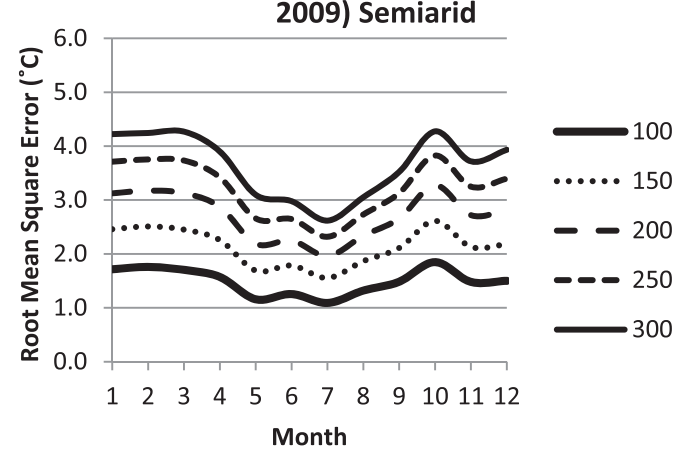

c. GudmundsenResearch (AWDN)Tmax (2005-2009) Semiarid

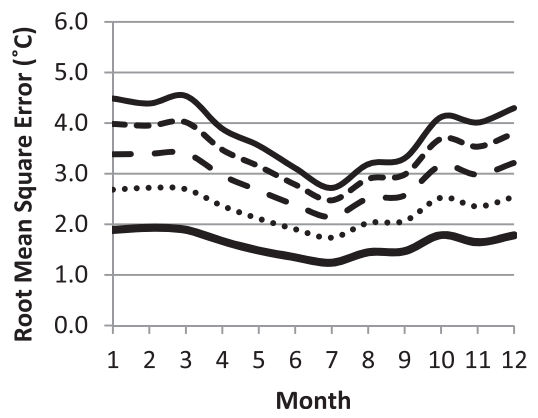

b. Whitman 5 ENE (CRN)-Tmin (20052009 Semiarid)

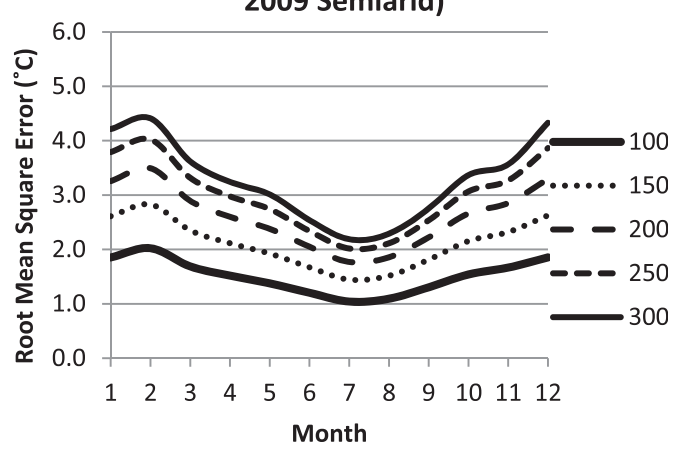

d. GudmundsenResearch (AWDN)Tmin (2005-2009) Semiarid

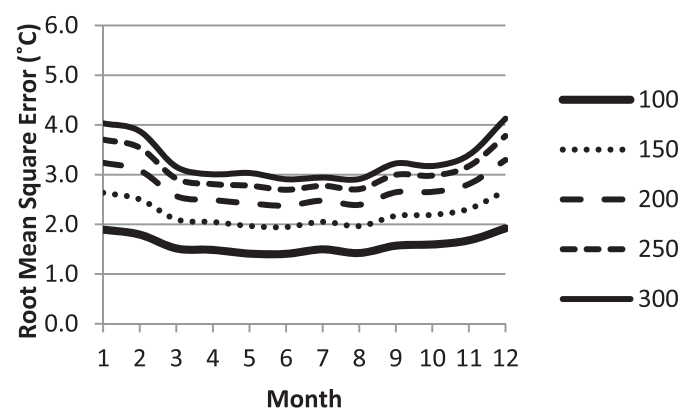

FIG. 6. RMSE $\left({ }^{\circ} \mathrm{C}\right)$ vs month for various distances $(\mathrm{km})$ from the candidate station to surrounding stations for semiarid sites for the Whitman 5 ENE CRN station for (a) Tmax and (b) Tmin and for the Gudmundsen Research Ranch AWDN station for (c) Tmax and (d) Tmin.

events such as cold and warm fronts may impact both stations, the sensor readings will not be in total synchronization.

This study shows, for the comparison (refer to Table 1) between HCN and AWDN, that the AWDN has higher spatial accuracy than $\mathrm{HCN}$ in all months and for both maximum and minimum temperature. More than $50 \%$ of the values evaluated for maximum temperature were different by more than $0.5^{\circ} \mathrm{C}$, and the AWDN has lower error (higher spatial accuracy) for maximum temperature than does HCN. There were few occurrences where for minimum temperature the RMSE differences were $\geq 0.5^{\circ} \mathrm{C}$. We know there are heterogeneities present in the $\mathrm{HCN}$ daily data (station moves during the period studied, change in instrumentation, different times of observation, separation of the liquid column in LIG thermometer, etc.). Our results show a lower network accuracy for $\mathrm{HCN}$, which we assume is due to the heterogeneity of $\mathrm{HCN}$ data.

This study found that, for the comparison between CRN and AWDN networks, the spatial error from the two networks was comparable; that is, the RMSEs were not often different by more than $0.5^{\circ} \mathrm{C}$ and no differences were found that were greater than $1^{\circ} \mathrm{C}$. This result seems logical because neither network is plagued with the reductions in accuracy that are due to changes in site location, changes in observation time, or changes in sensors (within a network). We conclude that networks with PRT sensors are not clearly superior to networks with thermistor sensors when comparing the spatial accuracy.

This study presents a quantitative baseline for Nebraska of how accuracy decreases as separation distance increases within these networks. The need for continued research and due diligence to ensure that climate networks are collecting reliable data remains. As research continues, we increase our knowledge about calibration of instruments, consistency in observation time, and consistency in location. This will help us to create, deploy, and improve networks. We found the spatial accuracy of networks to be seasonally dependent in Nebraska, with the higher accuracy associated with the summer season relative to winter. The networks were also somewhat more accurate in the subhumid part of the state as 
TABLE 2. RMSE $\left({ }^{\circ} \mathrm{C}\right)$ vs distance $(\mathrm{km})$ for each station in the pair (CRN and AWDN) for January and June 2005-09. An asterisk indicates that the RMSE at the given distance and station is lower by at least $0.5^{\circ} \mathrm{C}$ than the comparison station in the other network.

\begin{tabular}{|c|c|c|c|c|c|c|c|c|c|c|c|}
\hline \multirow[b]{2}{*}{ Candidate station by pairs } & \multirow[b]{2}{*}{ Month } & \multicolumn{5}{|c|}{$\begin{array}{l}\text { RMSE for max temperature at } \\
\text { various distances }(\mathrm{km})\end{array}$} & \multicolumn{5}{|c|}{$\begin{array}{l}\text { RMSE for min temperature at } \\
\text { various distances }(\mathrm{km})\end{array}$} \\
\hline & & 100 & 150 & 200 & 250 & 300 & 100 & 150 & 200 & 250 & 300 \\
\hline \multirow[t]{2}{*}{ Harrison 20 SSE (CRN), semiarid } & Jan & 1.89 & 2.70 & 3.41 & 4.04 & 4.57 & 2.17 & 3.04 & 3.78 & 4.38 & 4.84 \\
\hline & Jun & 1.19 & 1.72 & 2.19 & 2.62 & 2.99 & 1.68 & 2.34 & 2.87 & 3.27 & 3.55 \\
\hline \multirow[t]{2}{*}{ Mitchell Farms (AWDN), semiarid } & Jan & 1.91 & 2.69 & 3.37 & 3.94 & 4.39 & 1.80 & $2.52 *$ & $3.14^{*}$ & $3.64 *$ & $4.04 *$ \\
\hline & Jun & 1.46 & 2.07 & 2.60 & 3.05 & 3.42 & 1.26 & $1.74 *$ & $2.13^{*}$ & $2.43 *$ & $2.63^{*}$ \\
\hline \multirow[t]{2}{*}{ Lincoln 8 ENE (CRN), subhumid } & Jan & 1.65 & 2.36 & 2.97 & 3.50 & 3.95 & 1.28 & $1.88^{*}$ & $2.44^{*}$ & 2.97 & 3.46 \\
\hline & Jun & 1.01 & 1.44 & 1.81 & 2.13 & 2.40 & 1.07 & 1.52 & 1.90 & 2.23 & 2.49 \\
\hline \multirow{2}{*}{ Havelock (AWDN), subhumid } & Jan & 1.77 & 2.50 & 3.13 & 3.66 & 4.08 & 1.75 & 2.42 & 2.97 & 3.38 & 3.67 \\
\hline & Jun & 1.26 & 1.76 & 2.16 & 2.48 & 2.70 & 1.16 & 1.60 & 1.96 & 2.23 & 2.41 \\
\hline \multirow[t]{2}{*}{ Lincoln 11 SW (CRN), subhumid } & Jan & 1.68 & 2.39 & 3.00 & 3.53 & 3.96 & 1.05 & $1.57 *$ & $2.08^{*}$ & 2.58 & 3.07 \\
\hline & Jun & 1.10 & 1.56 & 1.96 & 2.32 & 2.61 & 1.07 & 1.51 & 1.88 & 2.20 & 2.44 \\
\hline \multirow[t]{2}{*}{ Lincoln 27E 56S (AWDN), subhumid } & Jan & 1.74 & 2.47 & 3.10 & 3.64 & 4.08 & 1.49 & 2.08 & 2.57 & 2.97 & 3.26 \\
\hline & Jun & 1.27 & 1.77 & 2.18 & 2.50 & 2.73 & 1.10 & 1.53 & 1.88 & 2.14 & 2.33 \\
\hline \multirow[t]{2}{*}{ Whitman 5 ENE (CRN), semiarid } & Jan & 1.72 & 2.46 & 3.12 & 3.71 & 4.22 & 1.85 & 2.61 & 3.26 & 3.79 & 4.21 \\
\hline & Jun & 1.26 & 1.78 & 2.25 & 2.65 & 2.98 & 1.20 & 1.67 & 2.05 & 2.34 & 2.54 \\
\hline \multirow[t]{2}{*}{ Gudmundsen (AWDN), semiarid } & Jan & 1.89 & 2.68 & 3.38 & 3.98 & 4.49 & 1.89 & 2.64 & 3.24 & 3.71 & 4.03 \\
\hline & Jun & 1.34 & 1.90 & 2.38 & 2.78 & 3.11 & 1.41 & 1.95 & 2.38 & 2.70 & 2.91 \\
\hline
\end{tabular}

compared with the semiarid area. We conclude that spatial accuracy will vary with seasons at a site and between areas with different climate types (arid, semiarid, subhumid, and humid).

This information is useful in assessing the uncertainty in assuming the measurements from a nearby weather station are applicable to the point where a climaterelated decision is to be made. Further, the uncertainty in initialization of models at grid points with data from a weather station some distance from the grid can be assessed. We conclude that the spatial accuracy information is useful to those who wish to expand an existing network in such a manner as to achieve the greatest reduction in uncertainty.

Acknowledgments. This work was partially supported by the University of Nebraska-Lincoln Hatch Research Funds.

\section{REFERENCES}

Coop, A. J., 2011: Spatial accuracy of climate networks in Nebraska. M.S. thesis, School of Natural Resources, University of Nebraska-Lincoln, 62 pp.

Davey, C. A., and R. A. Pielke, 2005: Microclimate exposures of surface-based weather stations: Implications for the assessment of long-term temperature trends. Bull. Amer. Meteor. Soc., 86, 497-504, doi:10.1175/BAMS-86-4-497.

Diamond, H. J., and Coauthors, 2013: U.S. Climate Reference Network after one decade of operations: Status and assessment. Bull. Amer. Meteor. Soc., 94, 489-498, doi:10.1175/ BAMS-D-12-00170.1.
Fiebrich, C. A., 2009: History of surface weather observations in the United States. Earth-Sci. Rev., 93, 77-84, doi:10.1016/ j.earscirev.2009.01.001.

Gallo, K. P., 2005: Evaluation of temperature differences for paired stations of the U.S. Climate Reference Network. J. Climate, 18, 1629-1636, doi:10.1175/JCLI3358.1.

Goody, R., J. Anderson, T. Karl, R. B. Miller, G. North, J. Simpson, G. Stephens, and W. Washington, 2002: Why monitor the climate? Bull. Amer. Meteor. Soc., 83, 873-878, doi:10.1175/ 1520-0477(2002)083<0873:WWSMTC >2.3.CO;2.

Guttman, N. B., and C. B. Baker, 1996: Exploratory analysis of the difference between temperature observations recorded by ASOS and conventional methods. Bull. Amer. Meteor. Soc., 77, 2865-2873, doi:10.1175/1520-0477(1996)077<2865: EAOTDB $>2.0 . \mathrm{CO} ; 2$.

Holder, C., R. Boyles, A. Syed, D. Niyogi, and S. Raman, 2006: Comparison of collocated automated (NCECONet) and manual (COOP) climate observations in North Carolina. J. Atmos. Oceanic Technol., 23, 671-682, doi:10.1175/JTECH1873.1.

Hoogenboom, G., and D. D. Gresham, 1997: Automated weather station network. Proc. 1997 Georgia Water Resources Conf., Griffin, GA, University of Georgia, 483-486. [Available online at http://www.gwri.gatech.edu/sites/default/files/files/ docs/1997/HoogenboomG-97.pdf.]

Hubbard, K. G., 1994: Spatial variability of daily weather variables in the high plains of the USA. Agric. For. Meteor., 68, 29-41, doi:10.1016/0168-1923(94)90067-1.

_ , and J. You, 2005: Sensitivity analysis of quality assurance using the spatial regression approach-A case study of the maximum/minimum air temperature. J. Atmos. Oceanic Technol., 22, 1520-1530, doi:10.1175/JTECH1790.1.

—, N. J. Rosenberg, and D. C. Nielsen, 1983: Automated Weather Data Network for agriculture. J. Water Resour. Plann. Manage., 109, 213-222, doi:10.1061/(ASCE)0733-9496(1983)109:3(213).

—, X. Lin, C. B. Baker, and B. Sun, 2004: Air temperature comparison between the MMTS and the USCRN temperature 
systems. J. Atmos. Oceanic Technol., 21, 1590-1597, doi:10.1175/ 1520-0426(2004)021<1590:ATCBTM>2.0.CO;2.

,-- , and -2005 : On the USCRN temperature system. J. Atmos. Oceanic Technol., 22, 1095-1101, doi:10.1175/ JTECH1715.1.

Janis, M. J., K. G. Hubbard, and K. T. Redmond, 2004: Station density strategy for monitoring long-term climatic changes in the continuous United States. J. Climate, 17, 151-162, doi:10.1175/1520-0442(2004)017<0151:SDSFML>2.0.CO;2.

Kemp, W. P., D. G. Burnell, D. O. Everson, and A. J. Thomson, 1983: Estimating missing daily maximum and minimum temperatures. J. Climate Appl. Meteor., 22, 1587-1593, doi:10.1175/ 1520-0450(1983)022<1587:EMDMAM > 2.0.CO;2.

Lawrimore, J. H., M. J. Menne, B. E. Gleason, C. N. Williams, D. B. Wuertz, R. S. Vose, and J. Rennie, 2011: An overview of the Global Historical Climatology Network monthly mean temperature data set, version 3. J. Geophys. Res., 116, D19121, doi:10.1029/2011JD016187.

Lin, X., and K. G. Hubbard, 2004: Sensor and electronic biases/ errors in air temperature measurements in common weather station networks. J. Atmos. Oceanic Technol., 21, 1025-1032, doi:10.1175/1520-0426(2004)021<1025:SAEEIA>2.0.CO;2.

_, and _ 2008: What are daily maximum and minimum temperatures in observed climatology? Int. J. Climatol., 28, 283-294, doi:10.1002/joc.1536.

- _ - E. A. Walter-Shea, J. R. Brandle, and G. E. Meyer, 2001: Some perspectives on recent in situ air temperature observations: Modeling the microclimate inside the radiation shields. J. Atmos. Oceanic Technol., 18, 1470-1484, doi:10.1175/ 1520-0426(2001)018<1470:SPORIS > 2.0.CO;2.

Melvin, M. J., A. I. Zygielbaum, D. Gutzmer, S. Rentschler, J. Bower, and K. G. Hubbard, 2008: Network variability for sensor accuracy and precision: A case study to assess atmospheric variability in simple terrain. Int. J. Climatol., 28, 267272, doi:10.1002/joc.1565.

Menne, M. J., C. N. Williams Jr., and R. S. Vose, 2009: The U.S. Historical Climatology Network monthly temperature data, version 2. Bull. Amer. Meteor. Soc., 90, 993-1007, doi:10.1175/ 2008BAMS2613.1.

— I. Durre, R. S. Vose, B. E. Gleason, and T. G. Houston, 2012: An overview of the Global Historical Climatology NetworkDaily database. J. Atmos. Oceanic Technol., 29, 897-910, doi:10.1175/JTECH-D-11-00103.1.

— C. N. Williams Jr., and R. S. Vose, cited 2013: United States Historical Climatology Network long-term daily and monthly climate records from stations across the contiguous United States. Oak Ridge National Laboratory Carbon Dioxide Information Analysis Center. [Available online at http://cdiac. ornl.gov/epubs/ndp/ushen/ushen.html.]

Meyer, S. J., and K. G. Hubbard, 1992: Nonfederal automated weather stations and networks in the United States and Canada: A preliminary survey. Bull. Amer. Meteor. Soc., 73, 449-457, doi:10.1175/1520-0477(1992)073<0449: NAWSAN $>2.0 . \mathrm{CO} ; 2$.

Pielke, R., and Coauthors, 2007: Documentation of uncertainties and biases associated with surface temperature measurement sites for climate change assessment. Bull. Amer. Meteor. Soc., 88, 913-928, doi:10.1175/BAMS-88-6-913.

Vose, R. S., and M. J. Menne, 2004: A method to determine station density requirements for climate observing networks. J. Climate, 17, 2961-2971, doi:10.1175/1520-0442(2004)017<2961: AMTDSD $>2.0 . C O ; 2$.

Wendland, W. M., and W. Armstrong, 1993: Comparison of maximum-minimum resistance and liquid-in-glass thermometer records. J. Atmos. Oceanic Technol., 10, 233-237, doi:10.1175/ 1520-0426(1993)010<0233:COMRAL>2.0.CO;2.

Wu, H., K. G. Hubbard, and J. You, 2005: Some concerns when using data from the cooperative weather station networks: A Nebraska case study. J. Atmos. Oceanic Technol., 22, 592-602, doi:10.1175/JTECH1733.1.

You, J., K. G. Hubbard, and S. Goddard, 2008: Comparison of methods for spatially estimating station temperatures in a quality control system. Int. J. Climatol., 28, 777-787, doi:10.1002/ joc.1571. 